\title{
Willingness to Take the Booster Vaccine in a Nationally Representative Sample of Danes
}

\author{
Frederik Juhl Jørgensen $^{1 *}$, Louise Halberg Nielsen ${ }^{1}$, Michael Bang Petersen ${ }^{1}$ \\ ${ }^{1}$ Department of Political Science, Aarhus University \\ *Corresponding author: fj@ps.au.dk
}

\begin{abstract}
$\underline{\text { Abstract }}$
We estimate the willingness to taking the booster dose in a representative sample of Danes. We estimate an overall willingness in the adult Danish population of 85.5 percent and a willingness of 94.7 percent among primary vaccine takers. We, moreover, show that these percentages will be significantly lower among younger populations as well as among groups who do not see COVID-19 as a threat towards society and who do not perceive the advice of the health authorities as effective against disease spread.
\end{abstract}

\section{Author contributions}

FJJ and MBP designed the study and collected the data in collaboration with Kantar Gallup. FJJ and LHN were responsible for analyzing and interpreting the data. FJJ and MBP wrote the first draft of the manuscript. All authors revised and approved the final version.

\section{$\underline{\text { Acknowledgements }}$}

We are grateful to Alexander Bor for helping in the design and collection of data. The Carlsberg Foundation grant number CF20-0044 to MBP supported the collection of data. 


\section{Setting}

The rapid world-wide spread of the Omicron variant of SARS-CoV-2 [1,2] is likely a combination of the variant's increased transmissibility and a rapidly waning immunity from vaccines against Omicron infection $[3,4]$. As a consequence, health authorities across the world are currently investing heavily in administering a third dose of vaccination (a so-called booster dose) to increase immunity $[3,4]$. This strategy poses a fundamental challenge because both epidemic control and epidemic forecasting (including via formal modeling) now hinges on assumptions about human behavior, specifically the proportion of the population that are willing to take up the booster dose [5]. The aim of this communication is to provide a robust estimate of the likely proportion of booster vaccine willingness using Danish data. Moreover, the communication aims at providing some guidance in what are the main drivers of willingness in order to assist communication efforts to promote booster dose acceptance.

\section{Surveillance of COVID-19 behavior in Denmark}

Since May 2020, we have been surveilling COVID-19 behavior and its psychological antecedents in daily national representative surveys of Danes. More specifically, we have surveyed approximately 500 (new) respondents each day (by now, the total $\mathrm{N}$ includes more than 350,000 individuals). Participants in the survey are Danish citizens aged 18 or older. They are recruited using stratified random sampling - on age, sex, and geography — based on the entire database of Danish social security numbers. The sample is thus representative of the Danish population. The response rate is about 25 percent. We did not employ any monetary incentives for participation. Participants are invited to take the survey via eBoks (the official electronic mail system used by the authorities and other institutions to communicate with citizens). Note that about 8 percent of the Danish population, mainly older people, are exempt from eBoks. Nonetheless, we observe that the sampled observations are close to the population margins with respect to sex, age, geographic region and vote choice at the last first order national election, while the sample is biased towards people with higher education and people among the adult population who have been vaccinated (see Table 1). To correct for these biases, we conduct the analyses on the weighted data that employs entropy balancing weights [6] to post-stratify the final sample data to fit the demographic margins.

Table 1. Population margins versus sample and weighted sample margins

\begin{tabular}{|l|c|c|c|}
\hline & Sample & Weighted sample & Population benchmark \\
\hline Vaccination & & & \\
\hline Fully vaccinated (2 jabs) & $94.8 \%$ & $88.0 \%$ & $88.0 \%$ \\
\hline Partially vaccinated (1 jab) & $0.7 \%$ & $1.7 \%$ & $1.7 \%$ \\
\hline Unvaccinated & $4.5 \%$ & $10.3 \%$ & $10.3 \%$ \\
\hline Education & & & \\
\hline Primary school & $10.1 \%$ & $25.2 \%$ & $25.1 \%$ \\
\hline Vocational & $22.7 \%$ & $29.5 \%$ & $29.5 \%$ \\
\hline High school & $11.1 \%$ & $10.9 \%$ & $10.9 \%$ \\
\hline Bachelor's degree & $36.6 \%$ & $23.0 \%$ & $23.0 \%$ \\
\hline Master's degree & $19.5 \%$ & $11.4 \%$ & $11.4 \%$ \\
\hline Sex x age & & & \\
\hline
\end{tabular}




\begin{tabular}{|l|c|c|c|}
\hline Female 18-29 years & $10.4 \%$ & $9.7 \%$ & $9.7 \%$ \\
\hline Female 30-39 years & $7.1 \%$ & $7.2 \%$ & $7.2 \%$ \\
\hline Female 40-49 years & $9.0 \%$ & $8.1 \%$ & $8.1 \%$ \\
\hline Female 50-59 years & $8.1 \%$ & $8.5 \%$ & $8.5 \%$ \\
\hline Female 60-69 years & $7.2 \%$ & $7.2 \%$ & $7.2 \%$ \\
\hline Female 70+ year & $7.2 \%$ & $9.9 \%$ & $9.9 \%$ \\
\hline Male 18-29 years & $12.2 \%$ & $10.1 \%$ & $10.1 \%$ \\
\hline Male 30-39 years & $6.2 \%$ & $7.5 \%$ & $7.5 \%$ \\
\hline Male 40-49 years & $9.2 \%$ & $8.1 \%$ & $8.1 \%$ \\
\hline Male 50-59 years & $7.6 \%$ & $8.6 \%$ & $8.6 \%$ \\
\hline Male 60-69 years & $8.3 \%$ & $7.0 \%$ & $7.0 \%$ \\
\hline Male 70+ year & $7.4 \%$ & $8.1 \%$ & $8.1 \%$ \\
\hline Region & & & \\
\hline Capitol & $31.7 \%$ & $31.8 \%$ & $31.7 \%$ \\
\hline Midtjylland & $22.9 \%$ & $22.6 \%$ & $22.6 \%$ \\
\hline Nordjylland & $10.5 \%$ & $10.2 \%$ & $10.2 \%$ \\
\hline Sjælland & $13.9 \%$ & $14.4 \%$ & $14.4 \%$ \\
\hline Syddanmark & $21.0 \%$ & $21.0 \%$ & $21.0 \%$ \\
\hline Party & & & $21.68 \%$ \\
\hline Socialdemokratiet & $23.03 \%$ & $21.68 \%$ & $7.22 \%$ \\
\hline Radikale Venstre & $6.95 \%$ & $7.21 \%$ & $5.54 \%$ \\
\hline Det Konservative Folkeparti & $7.98 \%$ & $5.54 \%$ & $1.97 \%$ \\
\hline Nye Borgerlige & $1.87 \%$ & $1.97 \%$ & $0.70 \%$ \\
\hline Klaus Riskær Pedersen & $0.30 \%$ & $0.70 \%$ & $6.45 \%$ \\
\hline Socialistisk Folkeparti & $5.68 \%$ & $6.45 \%$ & $1.95 \%$ \\
\hline Liberal Alliance & $2.67 \%$ & $1.95 \%$ & $1.44 \%$ \\
\hline Kristendemokraterne & $0.95 \%$ & $1.44 \%$ & $7.31 \%$ \\
\hline Dansk Folkeparti & $2.67 \%$ & $7.31 \%$ & $1.50 \%$ \\
\hline Stram Kurs & $0.11 \%$ & $1.50 \%$ & $5.81 \%$ \\
\hline Venstre & $15.31 \%$ & $19.58 \%$ & $2.47 \%$ \\
\hline Enhedslisten & $6.26 \%$ & $5.81 \%$ & \\
\hline Alternativet & $1.43 \%$ & $2.47 \%$ & \\
\hline Other & $24.79 \%$ & $16.38 \%$ & \\
\hline & & & \\
\hline
\end{tabular}

Since December 15, 2021, we included a question about participants willingness to take a booster dose. In particular, we ask participants "Have you received a third vaccine dose (a so-called booster jab)?" Below we present the overall distribution of responses on this measure (see Table). The analysis period is December 15 to December $19(\mathrm{~N}=2,731)$. Note, by December 21 the share of the adult population that had been revaccinated was 45.85 percent $^{1}$. Hence, our estimate of 44.95 has face validity. For the remainder of the analyses, we collapse response categories 1,3 and 5 into willingness to take the booster dose. We code the remaining categories $(2,4$ and 6$)$ as refusal Overall, this yields an estimate of the willingness to take the booster dose of 85.5 percent (95\% CI: 82.988.2).

\footnotetext{
${ }^{1}$ Number of revaccinated has been retrieved from the Danish Center for Disease Control [7] while the effective number of inhabitants aged 18 or older has been retrieved from Danish Statistics [8].
} 
Table 2. Distribution of responses

\begin{tabular}{|l|l|c|c|}
\hline $\begin{array}{l}\text { Response } \\
\text { category }\end{array}$ & Response label & Percent & $\mathbf{9 5 \% ~ C I ~}$ \\
\hline 1 & I have received the $3^{\text {rd }}$ vaccine dose & 44.95 & $42.37-47.52$ \\
\hline 2 & $\begin{array}{l}\text { I have received an invitation to the } 3^{\text {rd }} \text { vaccination dose, } \\
\text { but a do not wish the } 3^{\text {rd }} \text { dose }\end{array}$ & 1.26 & $0.74-1.79$ \\
\hline 3 & $\begin{array}{l}\text { I have not yet received the invitation to the } 3^{\text {rd }} \text { vaccination dose, } \\
\text { but I wish to be vaccinated with the } 3^{\text {rd }} \text { dose }\end{array}$ & 25.33 & $23.33-27.33$ \\
\hline 4 & $\begin{array}{l}\text { I have not yet received the invitation to the } 3^{\text {rd }} \text { vaccination dose, } \\
\text { and I do not wish to be vaccinated with the } 3^{\text {rd }} \text { dose }\end{array}$ & 9.43 & $7.02-11.84$ \\
\hline 5 & $\begin{array}{l}\text { I have received the invitation to the } 3^{\text {rd }} \text { vaccination dose, } \\
\text { and I wish to be vaccinated, but have not yet received the } 3^{\text {rd }} \text { dose }\end{array}$ & 15.22 & $13.52-16.93$ \\
\hline 6 & Do not want to answer & 3.80 & $2.46-5.14$ \\
\hline
\end{tabular}

\section{Characteristics of booster vaccine willingness}

The estimated 85.5 percent who would willingly take a booster vaccine among the adult Danish population compares to an estimated 90 percent in our sample of adult Danes who have responded that they are either (1) fully vaccinated (received 2 doses), (2) partially vaccinated (received 1 dose), or (3) wish to be vaccinated, but has previously refused an invitation. If we condition booster vaccine willingness on the 90 percent respondents who reported to be willing to take a vaccine, then we get an estimated booster vaccine willingness of 94.7 percent (95\% CI: 92.3-96.1). In other words, this implies that an assumption that those who accepted the primary vaccination will also automatically accept a booster dose does not seem valid. Specifically, we estimate that about 5 percent of those who accepted the primary vaccination will refuse to get the booster dose.

In Figure 1, we condition booster vaccine willingness on age and sex, respectively, both in the sample willing to take the primary vaccination (top panels) and in the full sample (bottom panels). In both samples, we observe a clear age pattern. The younger the participant, the less likely that she is willing to take the booster dose. For example, in the full sample, we observe that the estimated willingness to take the booster vaccine is 74.17 percent (95\% CI: 68.83-79.51) among respondents aged 18-29, 63.13 percent (95\% CI: 52.24-74.03) among 30-39, 85.38 percent (95\% CI: 80.03-90.72) among 40-49, 94.36 (95\% CI: 91.04-97.68) among 50-59, 98.13 percent (95 \% CI: 96.71-99.56) among 60-59, and 98.00 percent (95\% CI: 96.26-99.75) among respondents aged 70+. Unlike the clear age pattern, we observe no statistically meaningful differences in willingness across the sexes. 
Figure 1. Booster vaccine willingness, by age and sex
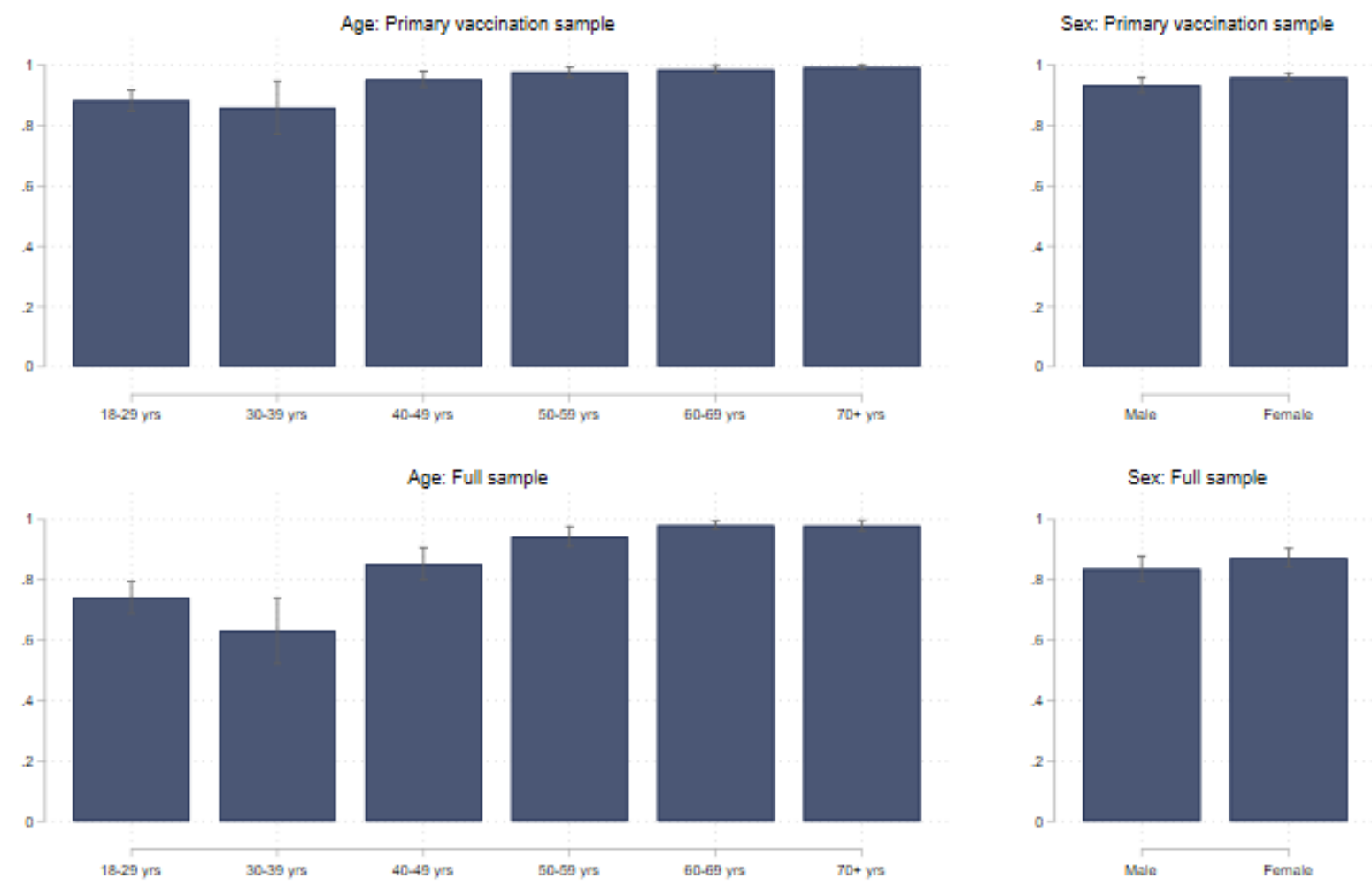

Note: Bars reflect the estimated willingness to take a booster dose. Whiskers denote $95 \%$ confidence intervals. Top panel reflects estimates from the vaccinated sample only $(2,613)$, while the bottom panel reflects estimates from the full sample $(\mathrm{N}=2,731)$.

In Table 3, we model booster vaccine willingness using OLS regression. Specifically, we regress willingness on the demographics discussed above and then important psychological antecedents related to protection motivation theory (PMT). The PMT factors include validated measures of personal threat appraisal, societal threat appraisal, self-efficacy, response efficacy, and response cost [9]. All concrete measurements are described in a previous study [10]. These factors have been demonstrated to be important for COVID-19 vaccine uptake [11] and other protective behaviors during the pandemic $[12,13]$ by previous studies. All continuous scales are centered on their mean. Coefficients for the scales can be interpreted as the change in booster vaccine willingness associated with a 2 standard deviation change in the respective predictor. Focusing on the sample that accepted primary vaccination, Table 3 confirms the demographic patterns discussed above. There is a clear difference between old and young with the elderly being more likely to accept the booster dose, while there is no heterogeneity across the sexes. Moving to the PMT factors, two factors stand out. Thus, societal threat and response efficacy is statistically significantly associated with booster vaccine willingness controlled for the remaining factors in the model. A 2 standard deviation increase in perceived threat to the society and efficacy of the response is associated with an estimated 4 and 5 percentage points increase in willingness, respectively. Turning attention to the full sample estimates, 
we observe the same empirical patterns, but just stronger, accounting for the fact that the correlates are strong predictors of also primary vaccination willingness [11].

Table 3. Booster vaccine willingness, regression results

\begin{tabular}{|c|c|c|c|c|}
\hline & \multicolumn{2}{|c|}{ Sample: Primary vaccination } & \multicolumn{2}{|c|}{ Sample: Full } \\
\hline & Estimate & $95 \% \mathrm{CI}$ & Estimate & $95 \% \mathrm{CI}$ \\
\hline \multicolumn{5}{|l|}{ Demographics } \\
\hline $18-29$ yrs & ref & ref & ref & ref \\
\hline $30-39$ yrs & 0.00 & $-0.06 ; 0.03$ & 0.01 & $-0.07 ; 0.08$ \\
\hline $40-49$ yrs & 0.05 & $0.00 ; 0.09$ & 0.07 & $0.00 ; 0.14$ \\
\hline $50-59$ yrs & 0.07 & $0.03 ; 0.11$ & 0.11 & $0.05 ; 0.17$ \\
\hline $60-69$ yrs & 0.06 & $0.02 ; 0.11$ & 0.13 & $0.07 ; 0.19$ \\
\hline $70+y r s$ & 0.06 & $0.01 ; 0.10$ & 0.11 & $0.11 ; 0.18$ \\
\hline Sex: male & ref & ref & ref & Ref \\
\hline Sex: female & 0.01 & $-0.01 ; 0.03$ & -0.01 & $-0.04 ; 0.03$ \\
\hline \multicolumn{5}{|l|}{ Protection motivation } \\
\hline Personal threat (2 sd) & 0.01 & $-0.01 ; 0.03$ & -0.04 & $-0.07 ; 0.00$ \\
\hline Societal threat (2 sd) & 0.04 & $0.02-0.07$ & 0.10 & $0.06 ; 0 ; 14$ \\
\hline Self-efficacy (2 sd) & 0.01 & $-0.03 ; 0.04$ & 0.03 & $-0.02 ; 0.07$ \\
\hline Response efficacy (2 sd) & 0.05 & $0.00 ; 0.09$ & 0.11 & $0.06 ; 0.16$ \\
\hline Response cost (2 sd) & -0.02 & $-0.04 ; 0.01$ & -0.01 & $-0.04 ; 0.03$ \\
\hline Constant & 0.88 & $0.81 ; 0.94$ & 0.74 & $0.65 ; 0.83$ \\
\hline $\mathrm{R}^{2}$ & \multicolumn{2}{|c|}{0.13} & \multicolumn{2}{|c|}{0.37} \\
\hline Observations & \multicolumn{2}{|c|}{1,974} & \multicolumn{2}{|c|}{2,056} \\
\hline
\end{tabular}

Note: Unstandardized (weighted) OLS regression coefficients with $95 \%$ confidence intervals. Robust standard errors.

\section{Discussion}

Given the rapid spread of the Omicron variant, a key aspect of epidemic control is populations' willingness to receive a booster vaccine against COVID-19. On the basis of high-quality data from Denmark, we estimate an overall willingness in the adult Danish population of 85.5 percent and a willingness of 94.7 percent among primary vaccine takers. These percentages, however, will be significantly lower among younger populations as well as among groups who do not see COVID-19 as a threat towards society ('societal threat') and who do not perceive the advice of the health authorities as effective against disease spread ('response efficacy').

For epidemic surveillance, including when doing formal modelling of the epidemic trajectory, it is important to consider the age-dependency of the willingness to receive booster vaccinations, even among those already vaccinated. For epidemic control, it is key for health communicators to engage in communication that addresses the concerns of those hesitant. Especially, there is a need to address why the spread of Omicron poses a threat to society and why booster vaccinations will enable societies to cope.

\section{Conclusion}

Health authorities can assume high willingness to receive a booster vaccination among those already vaccinated but willingness will decrease among younger groups as well as groups with lower concern and trust in the authorities. 


\section{References}

1. World Health Organization (WHO). Classification of Omicron (B.1.1.529): SARS-CoV-2 variant of concern. Geneva: WHO; 2021. Available

from: https://www.who.int/news/item/26-11-2021-classification-of-omicron-(b.1.1.529)sars-cov-2-variant-of-concern

2. Sundhedsministeriet. Omikron er den dominerende variants. Available from: https://sum.dk/ministeren/sociale-medier-arkiv/2021/december/2112-omikron-er-dendominerende-variant-

3. Bar-On, Y. M., Goldberg, Y., Mandel, M., Bodenheimer, O., Freedman, L., Kalkstein, N., ... \& Huppert, A. (2021). Protection of BNT162b2 vaccine booster against Covid-19 in Israel. New england journal of medicine, 385(15), 1393-1400.

4. Hansen, C., Schelde, A. Moustsen-Helm, I., Emborg, D., Krause, T., Mølbak, K. \& Valentiner, P. (2021). Vaccine effectiveness against SARS-CoV-2 infection with the Omicron or Delta variants following a two-dose or booster BNT162b2 or mRNA-1273 vaccination series: A Danish cohort study. medrxiv. Available from: https://www.medrxiv.org/content/10.1101/2021.12.20.21267966v1

5. Statens Serum Institut (SSI). Scenarios for infections and new admissions caused by the Omicron variant. Report by the Expert Group for Mathematic Modelling, 17 December 2021. Available from: scenarios-for-infections-and-new-admissions-caused-by-the-omicronvariant_201221.pdf

6. Hainmueller, J. (2012). Entropy balancing for causal effects: A multivariate reweighting method to produce balanced samples in observational studies. Political analysis, 20(1), 2546.

7. Statens Serum Institut (SSI). Færdigvaccinerede. Available from: https://experience.arcgis.com/experience/9824b03b114244348ef0b10f69f490b4/page/page 3/, retrieved December 21, 2021.

8. Statistikbanken (2021). Folketal den 1. i kvartalet efter køn, område, alder og tid. Available from: https://www.statistikbanken.dk/statbank5a/default.asp?w=1920, retrieved December 21, 2021.12.

9. Maddux, J. E., \& Rogers, R. W. (1983). Protection motivation and self-efficacy: A revised theory of fear appeals and attitude change. Journal of experimental social psychology, 19(5), 469-479.

10. BLINDED

11. Lindholt, M. F., Jørgensen, F., Bor, A., \& Petersen, M. B. (2021). Public acceptance of COVID-19 vaccines: cross-national evidence on levels and individual-level predictors using observational data. BMJ open, 11(6), e048172.

12. Jørgensen, F., Bor, A., \& Petersen, M. B. (2021). Compliance without fear: Individual-level protective behaviour during the first wave of the COVID-19 pandemic. British Journal of Health Psychology, 26(2), 679-696.

13. Jørgensen, F., Lindholt, M. F., Bor, A., \& Petersen, M. B. (2021). Does face mask use elicit risk-compensation? Quasi-experimental evidence from Denmark during the SARS-CoV-2 pandemic. European Journal of Public Health, 31(6), 1259-1265. 